\title{
The MASP online: The educational strategies from the museum in the pandemic
}

\author{
Keywords \\ Art, Cultural Mediation, MASP, Museum, Online.
}

This article has the target sharing the current research of master degree circumscribed into the Program of Post-graduation in Museology from Federal University of Bahia (PPGMuseum/ UFBA) oriented by Ph.d Ana Helena da S. Duarte. In our research we make inquiries into the action of cultural mediation proposed and done by the Museu de Arte de Sao Paolo - MASP during the COVID-19 pandemic. In such a way specially, though, on the Instagram Social Media this Museum interchanged and instigated your audience to learn, to interact and to produce with art objects from your collection. Therefore, through the educational strategies we consider Triangular Approach and Online Educational Museum foundation of your path. As mentioned previously the way to introduce the reader, in our research we investigated the online educational actions did it by the Museu de Arte de Sao Paolo MASP, at the moment of COVID-19 pandemic. The investigation pursues and explores the educational strategies elaborated, designed and done by the MASP and your team for your audience in the virtual place, i.e, the online mode. While theories reference, our base, it is three fundamental axis: Educational Theory of Paulo Freire(Educator and Brazilian Philosopher), and the influence into the Brazilian Educational Museum, Triangular Approach used firstly by Ana Mae Barbosa (educator, pioneer in art-education because of her systematization of the Triangular Approach) and the Greimassian's Semiotic Theory (Research line of Semiotic study the relation among plans of text circumscribed in relationship through the languages, created by Algirdas Julien Greimas, this theory made possible the investigation of the texts). Combined, brings to light the analysis of the production of the sense from the MASP's audience. Through of the discourses and texts produced by the Museum Educational team, mediated for Cultural Mediation in a constant dialogue with the concept of Online Educational Museum (OEM) proposed by the Researcher Frieda Marti (Ph.D from the Program of Post-Graduation Education College in the University of the State of Rio de Janeiro - PROPED/UERJ). In this logic, the methodological procedure of the research is based on theory approach and bibliography (theoretical instrumentalisation of concepts for the research) and the analytics investigation in a study case (the analysis of discourses of Online Cultural Mediation from MASP during the pandemic). Our highlight, our general objective, is set a relation between educational actions and the methodologic strategies in Online Cultural Mediation developed by MASP, mediated by analysis of the production made for the audience in this process, assumed the action in the virtual as a contribution for the Brazilian Educational Museum, in context of the pandemic and social isolation - from March 2020 to August 2021. For this purpose, our research problem is to think of the Educational Museum in the pandemic. Indeed our path is in the direction to enrich the Educational Museum, therefore one of the main objectives is reflecting and creating a healthy environment to debate the Educational Museum in the context of pandemic and social isolation in Brazil. 